\title{
Da Vedação ao Tratamento Desumano e Degradante no Direito Brasileiro
}

\section{IONILTON PEREIRA DO VALE}

Mestre em Direito pela UFC. Promotor de Justiça. Professor de Direito Processual Penal na FA7. ionilton@uol.com.br

Sumário: 1) Introdução; 2) A dignidade da pessoa humana considerações gerais; 3) A honra e sua proteção. Limites objetivos e subjetivos da honra; 4) Assédio moral e assédio sexual como forma de tratamento desumano e degradante; 5) Indenização por danos morais; 6) Considerações finais; 7) Referências bibliográficas.

Resumo: Importante corolário do princípio da dignidade da pessoa humana, a vedação ao tratamento desumano e degradante é importante passo dado pelo legislador constituinte na concretização dos diretos fundamentais. Constitui em direito fundamental de primeira geração que, embora de conteúdo negativo, impõe por parte do legislador e do Poder Judiciário, guardião dos direitos fundamentais, a efetiva vigilância e prestação, coibindo-se qualquer atentado ao status dignitatis do cidadão, tendo em vista a realização e implementação do princípio da igualdade material.

Palavras-chave: Dignidade da pessoa humana. Tratamento desumano e degradante. Honra-decoro. Honra-dignidade. Indenização. Assédio moral. Assédio sexual.

\section{$\infty$ INTRODUÇÃO}

A Constituição empresta muita importância à moral como valor ético-social da pessoa e da família, que se impõe ao respeito dos meios de comunicação social(art. 221, IV), realçando o valor da moral individual, tornando-a mesmo um bem indenizável (art. $5^{\circ}$, V e X). A moral individual sintetiza a honra da pessoa, o bom nome, a boa fama, a reputação que integram vida humana como dimensão 
imaterial. Ela e seus componentes são atributos sem os quais a pessoa fica reduzida a uma condição animal de pequena significação. No plano penal, a lesão à honra e dignidade, pode acarretar a abertura de ação criminal de natureza privada.

Consoante preleciona o artigo $5^{\circ}$, III - ninguém será submetido a tortura nem a tratamento desumano ou degradante. Tratamento desumano é aquele que contraria a própria natureza humana.Consoante a definição dos léxicos a palavra humano tem o sentido daquilo que é bondoso ou humanitário. Por seu turno degradante tem o significado daquilo que é aviltante, infamante e degradador (Dicionário Aurélio Século XXI).

Portador de uma imagem e autoconsciente de sua própria dignidade, o homem deve ter um tratamento compatível com seu status dignitates, prevendo a lei diversas cominações e sanções, inclusive penais, como é o caso do tratamento constitucional da tortura ${ }^{1}$, dos crimes contra a honra,calunia,injuria e difamação ${ }^{2}$,da injúria real ${ }^{3}$, resultando sanções também de natureza civil, como prevê a Constituição em seu artigo $5^{\circ}$, inciso V, que prevê indenização por dano moral, material ou à imagem. Trata-se de norma auto-aplicável com incidência inclusive na novel legislação civil que também prevê a indenização nos casos de crimes contra a honra ${ }^{4}$. Por seu turno, a lei 5.250, de setembro de 1967, regula a manifestação do pensamento.

Interessante e escorreita decisão do Supremo Tribunal Federal acerca do uso de algemas decidiu, sendo relatora a Ministra Carmem Lúcia, inexistir motivos para o uso de algemas, quando não tenha presentes as suas finalidades: a) impedir a fuga do acusado; b) evitar que o preso agrida outras pessoas ou a si mesmo ${ }^{5}$.

Lei 9.455 de 7 de abril de 1997.

2 Artigos 138,139 e 140 do Código Penal.

Artigo 139 § $2^{\circ}$ do Código Penal.

Artigo 953 do Código Civil.

5 "A Turma deferiu habeas corpus em que Conselheiro do Tribunal de Contas do Estado de Rondônia denunciado, com terceiros, com base em investigações procedidas na denominada 'Operação Dominó' pleiteava fosse a ele garantido o direito de não ser algemado e nem exposto à exibição para as câmeras da imprensa. (...) No tocante à necessidade ou não do uso de algemas, aduziu-se que esta matéria não é tratada, específica e expressamente, nos códigos Penal e de Processo Penal vigentes. Entretanto, salientou-se que a Lei de Execução Penal (art. 199) determina que o emprego de algema seja regulamentado por decreto federal, o que ainda não ocorreu. Afirmou-se que, não obstante a omissão legislativa, a utilização de algemas não pode ser arbitrária, uma vez que a forma juridicamente válida do seu uso pode ser inferida a partir da interpretação dos princípios jurídicos vigentes, especialmente o princípio da proporcionalidade e o da razoabilidade. Citaramse, ainda, algumas normas que sinalizam hipóteses em que aquela poderá ser usada (CPP, artigos 284 e 292; CF, art. 50, incisos III, parte final e X; as regras jurídicas que tratam de prisioneiros adotadas pela ONU , n. 33; o Pacto de San José da Costa Rica, art. $5^{\circ}$, 2). Entendeu-se, pois, que a prisão não é espetáculo e que o uso legítimo de algemas não é arbitrário, sendo de natureza excepcional e que deve ser adotado nos casos e com as finalidades seguintes: a) para impedir, prevenir ou dificultar a fuga ou reação indevida do preso, desde que haja fundada suspeita ou justificado receio de que tanto venha a ocorrer; b) para evitar agressão do preso contra os próprios policiais, contra terceiros ou contra si mesmo. Concluiu-se que, no caso, não haveria motivo para a utilização de algemas, já que o paciente não demonstrara reação violenta ou inaceitação das providências policiais. Ordem concedida para determinar às autoridades tidas por coatoras que se abstenham de fazer uso de algemas no paciente, a não ser em caso de reação violenta que venha a ser por ele adotada e que coloque em risco a sua segurança ou a de terceiros, e que, em qualquer situação, deverá ser imediata e motivadamente comunicado ao STF." (HC 89.429, Rel. Min. Carmem Lúcia, Informativo 437) 


\section{c A Dignidade da Pessoa Humana - Considerações Gerais}

O evolver das lutas sociais contra o arbítrio do soberano foi, historicamente, desenvolvendo o conceito de dignidade humana, e, juntamente com este, os conceitos de igualdade, liberdade e fraternidade.

A longa evolução histórica, de transformações sociais e religiosas, contribuiu para o reconhecimento da dignidade do homem, e de sua positivação em diversos documentos espaçados pelo tempo e espaço.

Infere-se, portanto, na história, em inúmeros documentos consagradores de direitos fundamentais, a elegia à dignidade do homem, no que foi seguido pela atual constituição em seu art. $1^{\circ}$, inciso III.

O primeiro documento dessa natureza foi uma lista de direitos que o Rei Afonso IX concedeu em 1188, às cortes parlamentares de representação corporativa do reino de Espanha. Nesse documento se encontram, por exemplo, o direito do acusado ao ordenamento regular do Processo, o direito à integridade da vida, honra, casa e propriedade ${ }^{6}$.

Posteriormente, o princípio da dignidade humana foi se incorporando às diversas constituições, constituindo-se em cláusula pétrea e fundamento dos estados democráticos, sendo a República Federal da Alemanha a primeira nação a agasalhar o princípio, em sua "Lex Fundamentalis", que incorporou um núcleo intocável de direitos fundamentais e humanos: eles são garantidos pela Constituição. É o que preleciona o artigo primeiro: "A dignidade do homem é intangível. Respeitá-la e protegê-la é a obrigação de todo poder Público”.

Analisando o princípio da dignidade da pessoa humana, o Tribunal Constitucional Federal Alemão, em interessante decisão em controle concentrado de constitucionalidade decidiu que, embora constitucional a pena de prisão perpétua imposta ao condenado, ante o atual estágio científico do conhecimento deve haver conciliação da execução com a dignidade humana que, em princípio, deve dar ao condenado alguma chance de um dia voltar à liberdade, não sendo suficiente a possibilidade de indulto ${ }^{7}$.

O Supremo Tribunal Federal em idêntica decisão, sendo relator o eminente ministro Marco Aurélio, entendeu que "a progressão no regime de cumprimento da pena, nas espécies fechado, semi-aberto e aberto, tem como razão maior a ressocialização do preso que, mais dia ou menos dia, voltará ao convívio social. PENA - CRIMES HEDIONDOS - REGIME DE CUMPRIMENTO PROGRESSÃO - ÓBICE - ARTIGO $2^{\circ}$, § $1^{\circ}$, DA LEI N ${ }^{\circ} 8.072 / 90$ INCONSTITUCIONALIDADE - EVOLUÇÃO JURISPRUDENCIAL. Conflita

${ }^{6}$ MALUSCHKE, Günter. Desenvolvimento Histórico dos Direitos Humanos, p.54.

${ }^{7}$ Cinqüenta anos de Jurisprudência do Tribunal Constitucional Federal alemão, pg. 181. 
com a garantia da individualização da pena - artigo $5^{\circ}$, inciso XLVI, da Constituição Federal - a imposição, mediante norma, do cumprimento da pena em regime integralmente fechado. Nova inteligência do princípio da individualização da pena, em evolução jurisprudencial, assentada a inconstitucionalidade do artigo $2^{\circ}$, § $1^{\circ}$, da Lei $\mathrm{n}^{\circ}$ 8.072/90 ${ }^{8}$ '. Referida decisão teve como elemento norteador o princípio da dignidade da pessoa humana, alterando o posicionamento do Supremo Tribunal Federal acerca do tema9 .

$\mathrm{Na}$ atualidade, pauta a tendência dos ordenamentos ao reconhecimento do ser humano como centro e o fim do direito. Esta inclinação foi reforçada após a segunda Guerra Mundial, ante as atrocidades cometidas pelo nazi-fascismo, encontrando-se plasmada a título de valor, nos Estados que adotam o modelo Democrático de Direito.

Atento às transformações mundiais, o Supremo Tribunal Federal inadmite a divisão de raças formada do núcleo do pensamento social nacionalista, em que prevalece a superioridade da raça ariana em detrimento dos judeus, paradigma da ideologia que levou ao extermínio e ao holocausto de seus cidadãos ${ }^{10}$.

A Constituição Italiana, de 27 de dezembro de 1947, deu guarida ao princípio em seu artigo $3^{\circ}$, quando afirmou: “Todos os cidadãos têm a mesma dignidade social e são iguais perante a lei”.

Nessa linha, a Constituição Portuguesa, promulgada em 1976, acentua em seu artigo $1^{\circ}$ princípio inerente aos direitos fundamentais:

"Portugal é uma República soberana, baseada entre outros valores na dignidade da pessoa humana e na vontade popular e empenhada na construção de uma sociedade livre”. Da mesma forma, a constituição da Espanha, advinda da derrocada do franquismo, assim a expressa: “A dignidade da pessoa humana, os direitos invioláveis que lhe são inerentes, o livre desenvolvimento da

${ }^{8}$ RHC 88997 / DF - DISTRITO FEDERAL RECURSO EM HABEAS CORPUS. Relator(a): Min. MARCO AURÉLIO. Julgamento: 08/08/2006. Órgão Julgador: Primeira Turma. Publicação: DJ 01-09-2006.

9 HC 88904/SP-SÃO PAULO. HABEAS CORPUS Relator: Min. RICARDO LEWANDOWSKI. Julgamento: 15/08/2006. Órgão Julgador: Primeira Turma .Publicação: DJ 01-09-2006.

10 "Fundamento do núcleo do pensamento do nacional-socialismo de que os judeus e os arianos formam raças distintas. Os primeiros seriam raça inferior, nefasta e infecta, características suficientes para justificar a segregação e o extermínio: inconciabilidade com os padrões éticos e morais definidos na Carta Política do Brasil e do mundo contemporâneo, sob os quais se ergue e se harmoniza o estado democrático. Estigmas que por si só evidenciam crime de racismo. Concepção atentatória dos princípios nos quais se erige e se organiza a sociedade humana, baseada na respeitabilidade e dignidade do ser humano e de sua pacífica convivência no meio social. Condutas e evocações aéticas e imorais que implicam repulsiva ação estatal por se revestirem de densa intolerabilidade, de sorte a afrontar o ordenamento infraconstitucional e constitucional do País." (HC 82.424-QO, Rel. Min. Maurício Corrêa, DJ 19/03/04) 
personalidade, o respeito pela lei e pelos direitos dos outros são fundamentos da ordem política e da paz social”.

A Carta das Nações Unidas, de 1945, traz em seu preâmbulo a referência à dignidade da pessoa humana, assim como a Declaração dos Direitos do Homem, elaborada pela ONU em 1948.

$\mathrm{O}$ artigo $1^{\circ}$ daquela declaração dispõe no sentido de que "todos os seres humanos nascem livres e iguais em dignidade e em direitos”.

Por seu turno, a Convenção Americana sobre Direitos Humanos, cujo texto foi aprovado em São José da Costa Rica, em 22.11.1969, integra hoje o sistema constitucional brasileiro. Sua aprovação pelo Brasil se deu pelo Decreto Legislativo 27, de 26.05.1992, que levou à sua ratificação pela Carta de adesão de 25.09.1992, vindo finalmente a ser incorporada ao direito interno pelo Decreto 678, de 06.11.1992, que determinou seu integral cumprimento. Assim dispõe em seu artigo 11, Proteção da honra e da dignidade:

“1. Toda pessoa tem direito ao respeito de sua honra e ao reconhecimento de sua dignidade.

2. Ninguém pode ser objeto de ingerências arbitrárias ou abusivas em sua vida privada, na de sua família, em seu domicílio em sua correspondência, nem de ofensas ilegais à sua honra ou reputação. "3. Toda pessoa tem direito à proteção da lei contra tais ingerências ou tais ofensas.”

A Convenção Européia não só declara o direito ao respeito da vida privada e familiar, do domicílio e da correspondência (art. $9^{\circ}$, n.1), mas ainda veda expressamente ingerências da autoridade pública no exercício desses direitos, salvo previsão legal e necessidade para a segurança pública, o bem-estar econômico do país, a defesa da ordem e a prevenção das infrações penais, a proteção da saúde ou da moral, ou a proteção dos direitos e liberdades de terceiros (art. $9^{\circ}$, n. 2).

A Constituição brasileira de 1988, no rol dos direitos individuais, no seu art. $5^{\circ}$ trouxe a lume importantes exigências que o Estado, no desenrolar de sua função punitiva, há de observar, sob pena de desrespeitar a dignidade da pessoa humana.

\section{(4 Aonra e sua Proteção. Limites ObJetivos e SubJetivos da Honra}

A proteção da honra sempre mereceu destaque por parte dos povos primitivos. O Código de Manu, por exemplo, cominava sanções rigorosas para as 
imputações difamatórias (v.g. penas de corte de língua, estilete de ferro em brasa, óleo fervendo pela boca e pagamento de multas). Em Roma, a honra era considerada como um direito público dos cidadãos, de modo que todos os fatos ofensivos a esse direito inseriam-se na noção ampla de injúria, que compreendia qualquer lesão voluntária e ilegítima à personalidade, em seus três aspectos: corpo, condição jurídica e honra.

A autonomia dos delitos contra a honra foi alcançada apenas em data recente. O Código Penal francês foi o responsável por elaborar, pela primeira vez, a distinção entre calúnia e injúria, significando aquela a imputação de fato delituoso ou difama-tório falso ou não comprovado verdadeiro; e esta a expressão de caráter ultrajante. Posteriormente, através de uma lei de 17 de maio de 1819, substituiu-se o termo calúnia por difamação e aboliu-se o requisito da falsidade do fato imputado. A legislação passou então a albergar duas espécies de ofensas à honra: a injúria e a difamação. A determinação do fato atribuído distinguia a difamação da injúria: enquanto a difamação consistia na imputação de fato determinado lesivo à honra ou à reputação de uma pessoa ou de uma instituição, a injúria compreendia toda expressão ultrajante ou de desprezo dirigida a outrem ${ }^{11}$.

A doutrina penal divide a honra em honra subjetiva e honra objetiva. A honra subjetiva é o sentimento de cada um a respeito de seus atributos físicos, intelectuais, morais e demais dotes da pessoa humana. É aquilo que cada um pensa a respeito de si mesmo em relação a tais atributos. Honra objetiva é a reputação, aquilo que os outros pensam a respeito do cidadão no tocante a seus atributos físicos, intelectuais, morais etc. Divide-se ainda a honra subjetiva em honra-dignidade e honra-decoro. Honra-dignidade é o conjunto de atributos morais do cidadão, honra-decoro é o conjunto de atributos físicos e intelectuais da pessoa ${ }^{12}$.

\section{\ Assédio Moral e Assédio Sexual como Forma de Tratamento Desumano e Degradante}

O tratamento desumano e degradante é óbice para o desenvolvimento pleno da personalidade, uma vez que esta implica liberdade de ação, tendo em vista que envolve a autodeterminação, a autoconservação e a auto-exposição.

Trata-se da esfera íntima do indivíduo que não pode ser desrespeitada sob pena de ferir-se o princípio da dignidade da pessoa humana.

Um exemplo de tratamento extremamente degradante foi fornecido por Hannah Arendt, quando relata o depoimento de um prisioneiro dos campos de concentração:

\footnotetext{
${ }^{11}$ PRADO, Luiz Regis. Curso de Direito Penal Brasileiro. Volume 2, Editora Revista dos Tribunais. São Paulo. 2004, p.234.

${ }^{12}$ JESUS, Damásio E. Direito Penal. Volume 2.Editora Saraiva. São Paulo. 2004, p. 202.
} 
"Grande parte do trabalho imposto nos campos de concentração era inútil; ou era supérfluo ou era tão mal planejado que tinha de ser feito duas ou três vezes. Os novos prisioneiros eram forçados a fazer tarefas idiotas, e sentiam-se degradados e preferiam trabalho mais pesado que produzisse alguma coisa de útil ${ }^{13}$ ”.

E arremata:

“Grande parte do tratamento imposto nos campos de concentração somente pôde acontecer porque os Direitos do Homem, apenas formulados, mas nunca filosoficamente estabelecidos, apenas proclamados, mas nunca politicamente garantidos, perderam em sua forma tradicional toda a validade ${ }^{14 \%}$.

Outras formas de tratamento degradante, além da própria tortura, são o assédio moral e o assédio sexual.

O assédio moral é conhecido na Itália, Alemanha e países escandinavos como mobbing; na Inglaterra e Estados Unidos como bullying; no Japão como ijime, nos países de língua espanhola como acoso moral ou acoso psicológico; e simplesmente assédio moral aqui no Brasil.

Caracteriza-se, segundo a doutrina, pela degradação deliberada das condições de trabalho em que prevalecem atitudes e condutas negativas dos chefes em relação a seus subordinados, constituindo uma experiência subjetiva que acarreta prejuízos práticos e emocionais para o trabalhador e a organização. A vítima escolhida é isolada do grupo sem explicações, passando a ser hostilizada, ridicularizada, inferiorizada, culpabilizada e desacreditada diante dos pares. Estes, por medo do desemprego e a vergonha de serem também humilhados associado ao estímulo constante à competitividade, rompem os laços afetivos com a vítima e, freqüentemente, reproduzem e reatualizam ações e atos do agressor no ambiente de trabalho, instaurando o pacto da tolerância e do silêncio no coletivo, enquanto a vítima vai gradativamente se desestabilizando e fragilizando, perdendo sua auto-estima. ${ }^{15}$

Trata-se de tratamento degradante, que fere o princípio da dignidade da pessoa humana, que pode, entre outras conseqüências, trazer para a vítima uma situação sem precedentes, abalando-lhe o ânimo e retirando-lhe a auto-estima. Enumera Marie-France Hirigoyen as seguintes conseqüências do assédio moral:

\footnotetext{
${ }^{13}$ ARENDT, Hannah. Origens do Totalitarismo. Companhia das Letras. 2000. São Paulo. P. 495.

${ }^{14}$ ARENDT, Hannnah.Ob. cit. P. 498.

${ }^{15}$ GUEDES, Márcia Novaes. Assédio Moral e responsabilidade das organizações com os direitos fundamentais dos trabalhadores. São Paulo: Revista da Amatra II, Dezembro de 2003, p. 38.
} 
“- Retirar da vítima autonomia. - Não lhe transmitir mais as informações úteis para a realização de tarefas. - Contestar sistematicamente todas as suas decisões. - Criticar seu trabalho de forma injusta ou exagerada. - Privá-la do acesso aos instrumentos de trabalho: telefone, fax, computador. - Retirar o trabalho que normalmente lhe compete. - Dar-lhe permanentemente novas tarefas. - Atribuir-lhe proposital e sistematicamente tarefas inferiores às suas competências. - Pressioná-la para que não faça valer seus direitos (férias, horários, prêmios). - Agir de modo a impedir que obtenha promoção. - Atribuir à vítima, contra a vontade dela, trabalhos perigosos. - Atribuir à vítima tarefas incompatíveis com sua saúde. Causar danos em seu local de trabalho. - Dar-lhe deliberadamente instruções impossíveis de executar. - Não levar em conta recomendações de ordem médica indicadas pelo médico do trabalho. - Induzir a vítima ao erro. 2. Isolamento e recusa de comunicação. A vítima é interrompida constantemente. - Superiores hierárquicos ou colegas não dialogam com a vítima. - A comunicação com ela é unicamente por escrito. - Recusam todo o contato com ela, mesmo o visual. - É posta separada dos outros. - Ignoram sua presença, dirigindo-se apenas aos outros. - Proíbem os colegas de lhe falar. - Já não a deixam falar com ninguém. - A direção recusa qualquer pedido de entrevista. 3. Atentado contra a dignidade. - Utilizam insinuações desdenhosas para qualificá-la. - Fazem gestos de desprezo diante dela (suspiros, olhares desdenhosos, levantar de ombros...). - É desacreditada diante dos colegas, superiores ou subordinados. Espalham rumores a seu respeito. - Atribuem-lhe problemas psicológicos (dizem que é doente mental). - Zombam de suas deficiências físicas ou de seu aspecto físico; é imitada ou caricaturada. - Criticam sua vida privada. - Zombam de suas origens ou nacionalidade. - Implicam com suas crenças religiosas ou convicções políticas. - Atribuem-lhe tarefas humilhantes. - É injuriada com termos obscenos ou degradantes. 4. Violência verbal, física ou sexual Ameaças de violência física. - Agridem-na fisicamente, mesmo que de leve, é empurrada, fecham-lhe a porta na cara. - Falam com ela aos gritos. - Invadem sua vida privada com ligações telefônicas ou cartas. - Seguem-na na rua, é espionada diante do domicílio. - Fazem estragos em seu automóvel. -É assediada ou agredida sexualmente (gestos ou propostas). - Não levam em conta seus problemas de saúde.”16

${ }^{16}$ HIRIGOYEN, Marie-France. Mal-Estar no Trabalho: redefinindo o assédio moral. Rio de Janeiro: Bertrand Brasil, 2002, p. 108. 
Juntamente com o assédio moral temos o assédio sexual. Este, por seu turno, se caracteriza como a conduta de "constranger alguém com o intuito de obter vantagem ou favorecimento sexual, prevalecendo-se o agente da sua condição de superior hierárquico ou ascendência inerente ao exercício de emprego, cargo ou função ${ }^{17}$ ”.

A doutrina especializada tem classificado o assédio sexual em duas espécies, com características diferenciais bem marcantes, que são o "assédio sexual por chantagem" e o "assédio sexual por intimidação"18".

A primeira forma tem como pressuposto necessário o abuso de autoridade, referindo-se à exigência feita por superior hierárquico (ou qualquer outra pessoa que exerça poder sobre a vítima), da prestação de "favores sexuais", sob a ameaça de perda de benefícios ou, no caso da relação de emprego, do próprio posto de trabalho.

Já a segunda espécie, também chamada de "assédio sexual ambiental”, é aquela que se caracteriza por incitações sexuais inoportunas, solicitações sexuais ou outras manifestações da mesma índole, verbais ou físicas, com o efeito de prejudicar a atuação de uma pessoa ou de criar uma situação ofensiva, hostil, de intimidação ou abuso no ambiente em que é intentado.

Tais condutas, como se infere, logicamente causam uma lesão moral ao indivíduo, propiciando-lhe uma indenização por danos morais.

\section{Indenização por Danos Morais}

Não há, por certo uma lei que determine um quantum na indenização por danos morais, mas não há dúvida de que a lesão sofrida pelo ofendido representa a dor moral ou anímica representada pela ofensa, e esta deve ser quantificável ${ }^{19}$. Embora haja respeitáveis opiniões em contrário, admitindo que a indenização por dano moral proporcional ao agravo refere-se ao direito de resposta ${ }^{20}$, entendemos que a proporcionalidade refere-se ao agravo, que deve ser aferida e arbitrada pelo Juiz.

Rui Stocco, estudioso da matéria, preleciona que se encontra pacificado o entendimento de que o dano moral é indenizável, afastadas as restrições, o preconceito, a má vontade que a doutrina pátria e alienígena impunham à tese ora

\footnotetext{
${ }^{17}$ Artigo 216-A do Código Penal Brasileiro.

${ }^{18}$ Barros, Alice Monteiro de, "O assédio sexual no Direito do Trabalho Comparado" in "Genesis - Revista de Direito do Trabalho”, vol. 70, Curitiba, Genesis Editora, outubro/98, p.503. Maiores informações podem ser obtidas no minucioso artigo de Jane Aeberhard-Hodges ("Womem Workers and the Courts" in "International Labour Review”, v. 135, n 5, 1996).

19 “O dano moral indenizável é o que atinge a esfera legítima de afeição da vítima, que agride seus valores, que humilha, que causa dor. A perda de uma frasqueira contendo objetos pessoais, geralmente objetos de maquiagem da mulher, não obstante desagradável, não produz dano moral indenizável.” (RE 387.014-AgR, Rel. Min. Carlos Velloso, DJ 25/06/04)

${ }^{20}$ FILHO, Fernando da Costa Tourinho. Manual de Processo Penal. São Paulo.Editora Saraiva.2005,p.214.
} 
esposada. Com o advento da nova ordem constitucional (CF/88), nenhum óbice se pode, a priori, antepor à indenização cumulada ${ }^{21}$. Referido ensinamento se coaduna com a jurisprudência do Supremo Tribunal Federal ${ }^{22}$.

De igual forma é pacífico o entendimento, inclusive no Supremo Tribunal Federal, de que a indenização por dano material não inviabiliza ou invalida a indenização por dano moral ${ }^{23}$.

Consoante o ensinamento de Alexandre de Morais, a indenização por danos morais terá cabimento seja em relação à pessoa física seja em relação à pessoa jurídica, e até mesmo em relação às coletividades (interesses difusos e coletivos); mesmo porque são todos titulares dos direitos e garantias fundamentais, desde que compatíveis com suas características de pessoas artificiais ${ }^{24}$. É de ressaltar, entretanto, que o dano moral da pessoa jurídica não alcança o nível constitucional a viabilizar a abertura da via extraordinária ${ }^{25}$.

\section{. Considerações Finais}

Não resta dúvida de que os direitos fundamentais, mais que o seu reconhecimento, impõem a sua plena concretização. O tratamento desumano e degradante atenta contra a própria condição humana, cuja vocação natural e indeclinável é a própria evolução social e espiritual e moral, cônscio de sua própria dignidade como sujeito ativo de seu próprio destino. A dignidade do homem, aliada a outros elementos como autoconsciência e autodeterminação devem ser, por parte dos poderes públicos, objeto de especial atenção, vinculando quer os poderes públicos, quer aos particulares, inobstante o silêncio da constituição.

Trata-se por evidente de norma auto-aplicável, independente de qualquer decisão por parte do poder público, tendo em vista que tem como escopo e proteção o próprio homem, e o faz dotado de dignidade especial.

\footnotetext{
${ }^{21}$ STOCCO, Rui. Responsabilidade Civil e sua Interpretação Jurisprudencial.São Paulo.Editora Revista dos Tribunais, 1995,p.444.

22 "Para a reparação do dano moral não se exige a ocorrência de ofensa à reputação do indivíduo. O que acontece é que, de regra, a publicação da fotografia de alguém, com intuito comercial ou não, causa desconforto, aborrecimento ou constrangimento, não importando o tamanho desse desconforto, desse aborrecimento ou desse constrangimento. Desde que ele exista, há o dano moral, que deve ser reparado, manda a Constituição, art. 5, X." (RE 215.984, Rel. Min. Carlos Velloso, DJ 28/06/02)

23 "O fato de a Convenção de Varsóvia revelar, como regra, a indenização tarifada por danos materiais não exclui a relativa aos danos morais. Configurados esses pelo sentimento de desconforto, de constrangimento, aborrecimento e humilhação decorrentes do extravio de mala, cumpre observar a Carta Política da República incisos V e X do artigo 5', no que se sobrepõe a tratados e convenções ratificados pelo Brasil." (RE 172.720, Rel. Min. Marco Aurélio, DJ 21/02/97). No mesmo sentido: AI 196.379-AgR, DJ 24/04/98.

${ }^{24}$ Moraes, Alexandre. Direitos Humanos Fundamentais. São Paulo. Editora Atlas. 2003, p.59.

25 "A possibilidade de a pessoa jurídica sofrer danos morais não alcança nível constitucional a viabilizar a abertura da via extraordinária." (RE 221.250-AgR, Rel. Min. Ellen Gracie, DJ 06/04/01)
} 
Os direitos de personalidade, enfim, só encontram terreno fértil quando do respeito aos direitos fundamentais do homem.

\section{RefERÊNCIAS BiBLIOgRÁficAS}

ALEXY, Robert. Direitos Fundamentais no Estado Constitucional Democrático. Rio de Janeiro, 217:55-66, jul/set 1999.

ARAÚJO FILHO, Aldy Mello. A Evolução dos Direitos Humanos, avanços e perspectivas. São Luiz (MA): EDUFMA, AAFMA, 1998.

ARENDT, Hannah. Origens do Totalitarismo. São Paulo: Companhia das Letras. 2000.

BICUDO, Hélio. Direitos Humanos e sua Proteção. São Paulo: FTD, 1997.

BOBBIO, Norberto. A Era dos Direitos. Rio de Janeiro: Campus, 1992.

BONAVIDES, Paulo. Política e Constituição. Os caminhos da democracia. Rio de Janeiro: Forense, 1985.

CICCO, Cláudio de. Kant e o Estado de Direito: O problema do fundamento da cidadania. São Paulo: Editora Revista dos Tribunais, 1995.

DIREITOS HUMANOS: Conquistas e desafios. Brasília: Letra Viva, 1999.

FILHO, Fernando da Costa Tourinho. Manual de Processo Penal. São Paulo: Saraiva, 2005.

MALUSCHKE, Günter. Desenvolvimento Histórico dos Direitos Humanos: Desafios da Ciência e daPrática. $1^{\text {a }}$ ed, Fortaleza: Konrad Adenauer.

MORAES, Alexandre. Direitos Humanos Fundamentais. São Paulo: Atlas, 2003.

PRADO, Luiz Regis. Curso de Direito Penal Brasileiro. Volume 2. São Paulo: Editora Revista dos Tribunais, 2004.

STOCCO, Rui. Responsabilidade civil e sua interpretação jurisprudencial. São Paulo: Revista dos Tribunais.

JESUS, Damásio E. Direito Penal. Volume 2. São Paulo: Saraiva, 2004. 


\section{PROHIBITION OF INHUMAN AND DEGRADING TREATMENT IN BRAZILIAN LAW}

Abstract: Considering human dignity, the prohibition of inhuman and degrading treatment is an important step to achieve this fundamental right. It is a right of first generation and imposes the state the task to avoid any attempt to the citizen status dignitatis, always envisaging the principle of material equality.

Keywords: Person's dignity. Inhuman and degrading treatment. Compensation. Sexual harassment. Moral harassment. 